\title{
KLASIFIKASI JENIS KENDARAAN RODA EMPAT MENGGUNAKAN EXTREME LEARNING MACHINE
}

\author{
Ina Najiyah', Salman Topiq \\ 1Universitas Adhirajasa Reswara Sanjaya \\ e-mail: inajiyah@ars.ac.id \\ 2Universitas Adhirajasa Reswara Sanjaya \\ e-mail: salman@ars.ac.id
}

\begin{abstract}
Abstrak
Kendaraan merupakan sebuah objek yang menjadi alat transportasi penduduk khususnya di Indonesia. Kendaraan roda empat saat ini sudah beranekaragam jenisnya mulai dari kendaraan kecil, sedang sampai kendaraan besar. Tujuan penelitian ini melakukan klasifikasi jenis kendaraan roda empat dengan bidang Image Processing. Metode yang dipilih adalah metode Extreme learning machine, dimana metode ini cukup baik dalam melakukan pemroresan gambar dan untuk klasifikasi. Penelitian ini mengklasifikasikan kedalam empat class yaitu class sedan, MVP, truck dan Bus dengan total masing-masing dataset 100 gambar. Hasil dari penelitian ini membuktikan bahwa metode Extreme learning machine baik untuk mengklasifikasikan kendaraan roda empat dengan akurasi baik yaitu $86 \%$ dan nilai precisionnya $82 \%$.
\end{abstract}

Kata Kunci: Klasifikasi Jenis Kendaraan, Extreme learning machine, Image Processing.

\begin{abstract}
Vehicle is an object that becomes a means of transportation for the population, especially in Indonesia. Currently, there are various types of four-wheeled vehicles ranging from small, medium to large vehicles. The purpose of this study is to classify the types of four-wheeled vehicles in the field of Image Processing. The method chosen is the Extreme learning machine method, where this method is quite good at processing images and for classification. This study classifies into four classes, namely sedan, MVP, truck and bus classes with a total of 100 images for each dataset. The results of this study prove that the Extreme learning machine method is good for classifying four-wheeled vehicles with a good accuracy of $92 \%$ and a precision value of $82 \%$.
\end{abstract}

Keywords: Classification of Vehicle Types, Extreme learning machine, Image Processing.

\section{Pendahuluan}

Jumlah kendaraan di Indonesia khususnya mobil semakin hari semakin meningkat kuantitasnya (Priyambodo, 2018). Kondisi meningkatnya jumlah kendaraan tersebut maka pemerintah menugaskan pihak kepolisian untuk memantau kondisi kendaraan tersebut di lalu lintas guna meningkatkan keamanan. Kondisi yang ada saat ini, penggunaan kamera pengintai di lalu lintas cukup membantu pihak kepolisian dalam memantau mobil-mobil yang dicurigai, hanya saja pengecekan dilakukan masih secara manual. Pengecekan secara manual tersebut masih belum cukup baik, dikarenakan waktu yang dibutuhkan kurang efisien serta tingkat keakurasian yang masih terbilang rendah sehingga dibutuhkan sebuah system untuk membantu mendeteksi mobil-mobil tersebut secara otomatis guna membantu pihak kepolisian dalam mengintai mobil dan tetap menjaga keamanan secara efektif. Sistem tersebut dapat dibantu dengan bidang teknologi informasi. Bidang teknologi informasi saat ini sudah banyak digunakan untuk membantu mengatasi berbagai macam permasalahan, salah satunya yaitu bidang Machine learning.

Machine learning merupakan salah satu bidang pembelajaran mesin dimana dapat membantu permasalahan seperti deteksi dan klasifikasi (Roihan et al., 2020). Machine learning dapat diusulkan dalam mengatasi permasalahan deteksi jenis 
kendaraan khususnya mobil. Ranah machine learning pernah dilakukan dalam mendeteksi kendaraan misalnya penelitian yang melakukan deteksi kendaraan mobil dengan menggunakan metode Region Of Interest (ROI) (Pratomo et al., 2020) penelitian lain melakukan deteksi kendaraan dengan algoritma yang berbasis deep learning dengan metode Radial Basis Function (Pangestuti et al., 2016), serta penelitian lain melakukan deteksi kendaraan bermobil menggunakan Klasifikasi Neural Network, Support Vector Machine, Dan Algoritma C4.5 (Purwaningsih, 2016).

Pada penelitian ini, penulis mengusulkan metode Extreme Machine learning (EML) guna membantu melakukan deteksi kendaraan bermobil dengan empat class yaitu mobil truck, sedan, MPV dan bus. Algoritma extreme learning machine (ELM) adalah metode pembelajaran Single Layer Feedforward Neural Network (SLFNs) yang menyederhanakan proses inisialisasi dan pelatihan berat. Extreme learning machine (ELM) berbeda dari metode pembelajaran tradisional dengan memilih secara acak bobot input dan selanjutnya secara analitik menentukan bobot output dengan menggunakan solusi linear kuadrat terkecil. Oleh karena itu tidak diperlukan algoritma berdasarkan gradient descent, seperti algoritma backpropagation.

Algoritma extreme learning machine (ELM) memiliki kelebihan yaitu pelatihan sangat cepat, membutuhkan lebih sedikit pengaturan parameter, dan hasilnya menghasilkan kinerja generalisasi yang baik (Najar et al., 2018). Berdasarkan penelitian (Fadilla et al., 2018) yang menghasilkan nilai akurasi sebesar 96,7\%. Dapat disimpulkan bahwa metode Extreme learning machine (ELM) cukup baik diimplementasikan untuk proses klasifikasi penyakit Chronic Kidney Disease (CKD).

Berdasarkan pemaparan tersebut, pada penelitian ini akan dilakukan klasifikasi jenis kendaraan roda empat meliputi sedan, MVP, bus dan truck dengan dataset berjumlah 400 data masing-masing 100 gambar.

\section{Metode Penelitian}

Pada sistem yang dibangun, skenario yang terjadi apabila pengguna mengakses sistem dan memasukan gambar mobil akan diketahui jenis mobil tersebut serta besaran akurasinya. Adapun prosedur dari sistem dapat dilihat pada gambar 1. berikut:

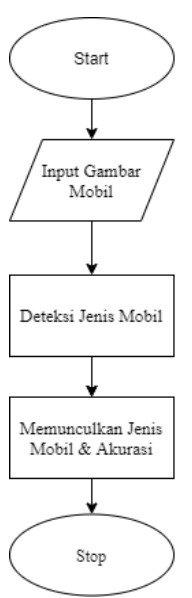

Gambar 1. Alur Prosedur Sistem Yang Dibangun

Adapun analisis sistem dari model Extreme learning machine yang dibangun seperti pada Gambar 2.

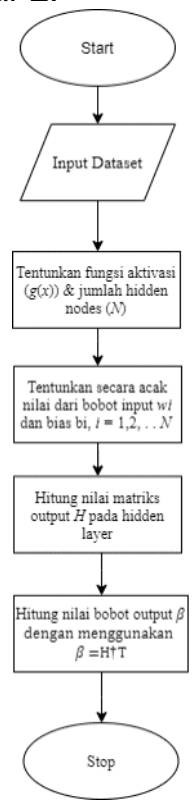

Gambar 2. Flowchart Extreme learning machine Yang Dibangun

Berikut ini adalah keterangan Flowchart Extreme learning machine Yang Dibangun :

1. Input Dataset

Data yang dikumpulkan adalah data gambar yang di dalamnya terdapat satu objek dari jenis mobil sedan, MVP, truk dan bus. Data gambar tersebut adalah gambar yang berwarna dengan ukuran yang bervariasi. Data gambar ini nantinya akan dibagi ke dalam dua kelompok yaitu data training dan data testing. 
2. Praproses Data

Agar dapat diproses oleh Extreme learning machine, maka data citra yang telah dikumpulkan harus melalui praproses terlebih dahulu. Praproses ini terdiri dari proses deteksi tepi, cropping, konversi citra warna ke grayscale, dan penyeragaman ukuran citra. Algoritma deteksi tepi yang digunakan adalah metode Canny. Setelah dilakukan deteksi tepi kemudian masing-masing tepi yang terdeteksi akan diberikan bounding box. Luas masing-masing bounding box tersebut kemudian dihitung dan dicari bounding box dengan luas terbesar untuk dilakukan proses cropping. Selanjutnya citra berwarna yang telah melalui proses cropping akan dikonversi menjadi citra grayscale dan dilakukan penyeragaman ukuran citra yaitu menjadi 50x50 piksel.

3. Pemodelan Extreme learning machine

ELM mempunyai model matematis yang berbeda dari jaringan syaraf tiruan feedforward. Model matematis dari ELM lebih sederhana dan efektif. Dengan 75 jumlah sampel yang berbeda $(x i, t i)$, jumlah hidden nodes sebanyak 1250 dan fungsi aktivasi $g(x)$ maka berdasarkan Persamaan didapatkan model matematis ELM pada penelitian ini sebagai berikut:

$$
\begin{aligned}
& \sum_{1} \beta i g i(\mathrm{xj})=1250 i=1 \sum \beta i g(w i . \mathrm{xj}+b i) \\
& =\text { oj } 1250 i=1, j=1,2, \ldots, 75 \\
& \text { di mana } \\
& \text { - wi }=[w i 1, \text { wi2, . . . , wi2500] } T \\
& \text { merupakan vektor bobot yang } \\
& \text { menghubungkan hidden node ke-i dan }
\end{aligned}
$$
input nodes.

- $\beta i=[\beta i 1, \beta i 2, \beta i 3] T$ merupakan vektor bobot yang menghubungkan hidden node ke-i dan output nodes.

- bi merupakan bias dari hidden node kei. dan $\times j$.

- wi . xj merupakan inner product dari wi

Berikut ini adalah penjabaran model pada setiap layer arsitektur jaringan:

a. Input Layer

Layer ini merupakan layer pertama pada jaringan. Layer ini terdiri dari $50 \times 50$ atau 2.500 node sesuai dengan ukuran citra input yang merupakan hasil dari praproses data. Satu piksel pada citra input mewakili satu node pada lapisan ini. Input layer dengan hidden layer dihubungkan oleh vektor bobot $w$ dan bias yang nilainya ditentukan secara acak. Fungsi yang dipilih sebagai fungsi aktivasi pada layer ini adalah fungsi softsign yaitu:

$f(x)=x 1+|x|$

Fungsi aktivasi ini memberikan batasan keluaran antara $(-1,1)$. Berdasarkan Persamaan tersebut dapat dirumuskan suatu fungsi umum sebagai berikut:

$H i, j=g(w i \cdot x j+b i)=w i \cdot x j+b i 1+$ $|w i \cdot \mathrm{xj}+b i|$

Keterangan variabel dan indeks pada persamaan di atas adalah sebagai berikut:

$H$ : matriks output pada hidden layer $w$ : vektor bobot yang menghubungkan hidden node dan input node.

$\mathrm{x}$ : vektor input

$b$ : bias yang terhubung dengan hidden node

$i$ : indeks jumlah node pada hidden layer

$j$ : indeks jumlah citra input $w$.

$\mathrm{x}$ : inner product dari $w$ dan $\mathrm{x}$

b. Hidden Layer

Layer ini merupakan layer kedua dari jaringan dan terdiri dari 1250 buah node. Hidden layer dan output layer dihubungkan oleh vektor bobot $\beta$. Sehingga berdasarkan Persamaan dengan $N=75$ dan $\tilde{N}=1250$ dapat dituliskan suatu persamaan sebagai berikut:

$H \beta=T$,

c. Output Layer

Setiap node yang ada di hidden layer dihubungkan dengan output layer melalui vektor bobot $\beta$. Jumlah node pada output layer disesuaikan dengan jumlah kelas dari objek yang akan dikenali. Output layer pada penelitian ini terdiri dari 4 buah node dan hasil keluaran dari output layer ini mewakili kelas dari citra input.

\section{Hasil dan Pembahasan}

Analisis arsitektur sistem merupakan tahapan pengidentifikasian arsitektur pada sistem yang dibangun. Pada pengidentifikasian arsitektur ini diberikan gambaran dari arsitektur sistem yang dibangun. Adapun arsitektur sistem dapat dilihat pada gambar 3 . berikut: 


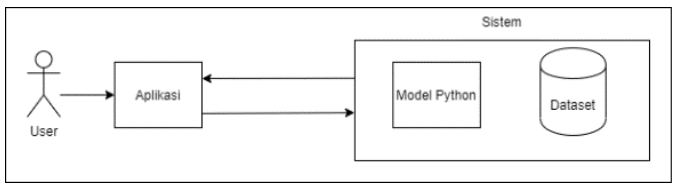

Gambar 3. Arsitektur Sistem Yang Dibangun

Berikut ini merupakan alur proses dari arsitektur sistem yang dibangun:

1. client mengakses aplikasi yang terinstall pada handphone android.

2. sistem melakukan manipulasi data yang dibutuhkan. Data diambil dari model yang dibuat.

3. data yang diambil dari dataset kemudian diolah agar sesuai dengan request dari client.

4. sistem menampilkan data sesuai request ke aplikasi user/client.

\section{Teknologi Yang Digunakan}

Analisis teknologi bertujuan untuk mengetahui teknologi apa saja yang akan digunakan sesuai dengan kebutuhan dalam sistem yang dibangun. Berikut merupakan teknologi yang digunakan pada sistem yang dibangun antara lain:

\section{a. Library Keras Python}

Ditulis dengan bahasa pemrograman Python, Keras adalah perpustakaan berbasis sumber terbuka yang dirancang untuk menyederhanakan model dari kerangka Deep Learning. Keras dapat dijalankan di atas framework (kerangka kerja) kecerdasan buatan seperti TensorFlow, Microsoft Cognitive Toolkit, dan Theano (Santoso \& Ariyanto, 2018). Pada penelitian ini keras digunakan dalam tahap training untuk melatih machine mengenali jenis mobil dan tingkat akurasinya pada dataset.

Berikut merupakan code library keras:

\begin{tabular}{c} 
from keras.utils import np_utils \\
from keras.models import \\
Sequential, load_model \\
from keras.layers import Dense, \\
Dropout, Activation, \\
Conv2D,MaxPooling2D, Flatten \\
\hline
\end{tabular}

\section{b. Library OpenCV}

OpenCV adalah sebuah library (perpustakaan) yang digunakan untuk mengolah gambar dan video hingga kita mampu meng-ekstrak informasi didalamnya. OpenCV dapat berjalan di berbagai bahasa pemograman, seperti $\mathrm{C}, \mathrm{C}_{++}$, Java, Python, dan juga support diberbagai platform seperti Windows, Linux, Mac OS, iOS dan Android.
Pada penelitian ini openCV digunakan untuk mengolah data mobil dengan format jpg (Sidharta, 2017). Berikut code openCV:

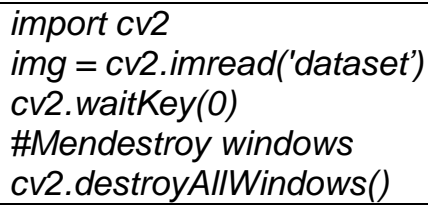

Proses penyelesaian masalah prediksi dengan Extreme learning machine (ELM) diawali dengan normalisasi data, kemudian melakukan proses training, lalu proses testing, selanjutnya dilakukan denormalisasi data dan perhitungan nilai error dengan menggunakan Mean Square Error (MSE).

Berikut merupakan proses pembahasan pada klasifikasi kendaraan.

\subsection{Normalisasi Data}

Normalisasi data dilakukan karena rentang nilai input tidak sama. Input akan diproses ke nilai output yang kecil sehingga data yang digunakan harus disesuaikan agar dapat diproses untuk mendapatkan nilai normalisasi yang kecil (Arifin, 2021). Dalam penelitian ini, data yang digunakan akan disesuaikan dengan cara menormalisasi data. Dataset yang digunakan pada penelitian ini yaitu image, maka proses normalisasi data adalah proses membagi gambar menjadi beberapa pixel dan menghapus bagian pixel yang tidak penting

Hal melakukan proses normalisasi data pada penelitian ini menggunakan code python. Berikut code python untuk melakukan proses normalisasi data.

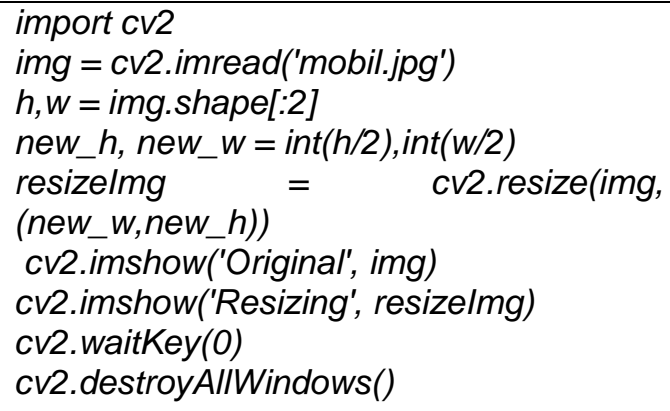

\subsection{Proses Training}

Proses training harus terlebih dahulu dilakukan sebelum proses prediksi.

Input dataset dilakukan dengan cara memanggil folder dataset melalui command 


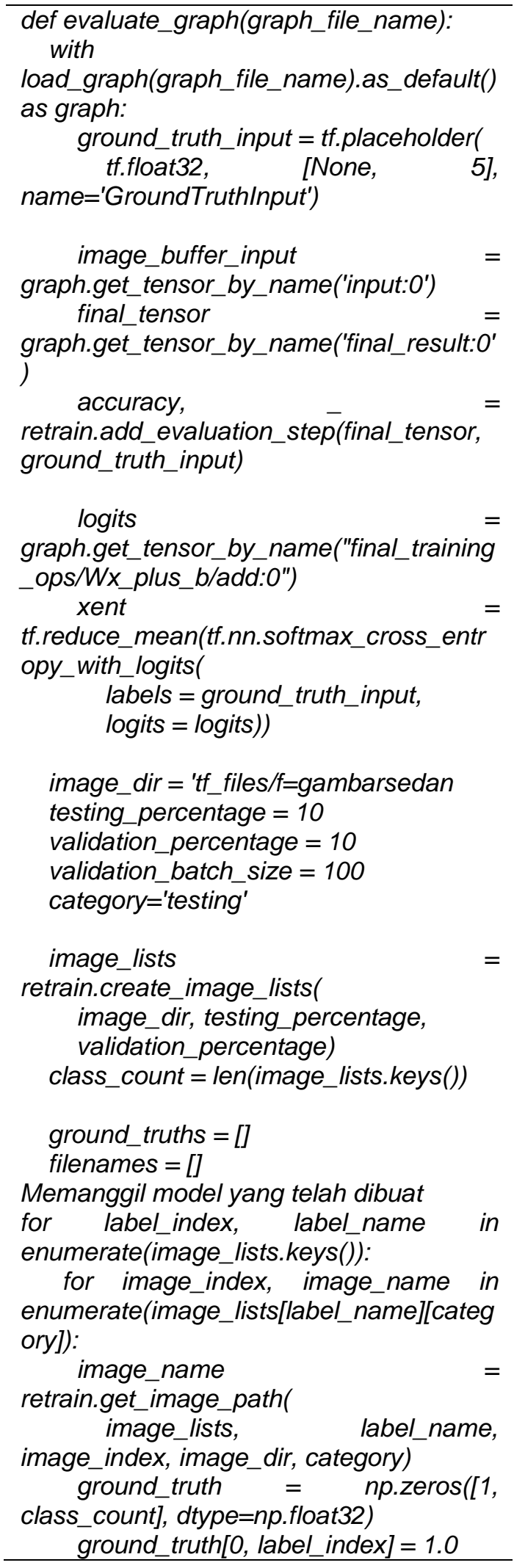

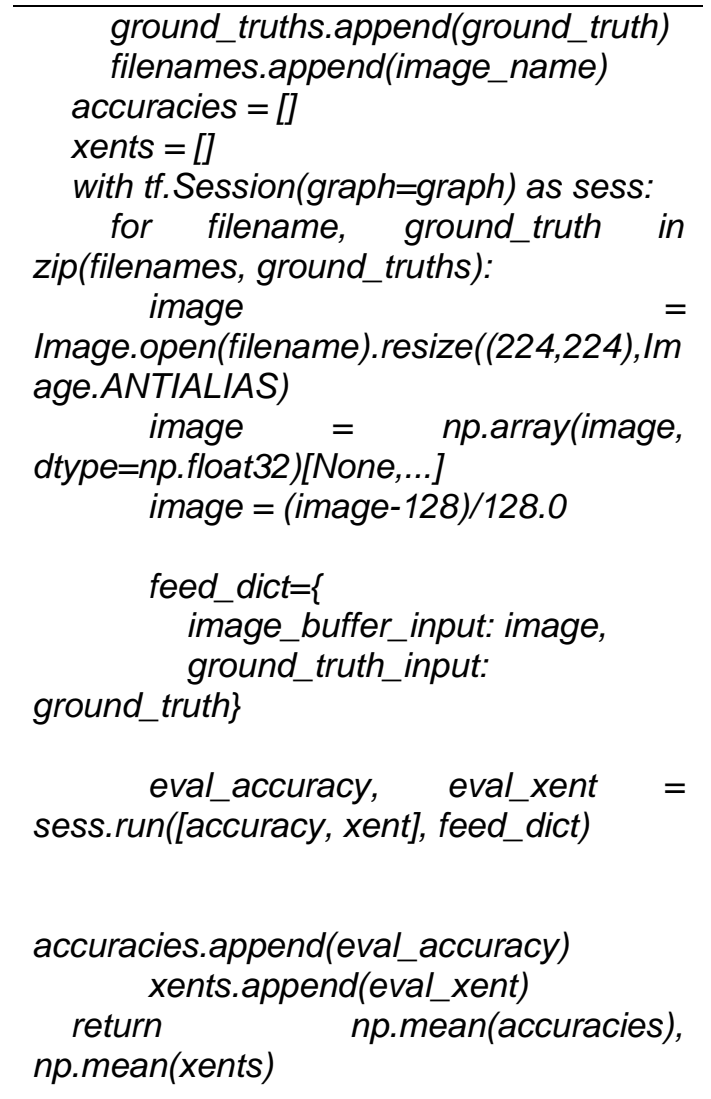

Mendeteksi jenis mobil

Setelah memanggil model, maka proses selanjutnya adalah deteksi mobil. Berikut merupakan code untuk mendeteksi jenis mobil

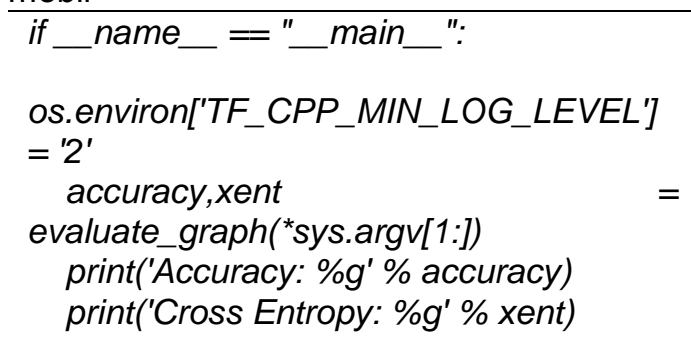

\subsection{Hasil Penelitian}

Hasil penelitian ini adalah aplikasi deteksi jenis mobil menggunakan metode Extreme learning machine dengan user interface pada Gambar 4. 


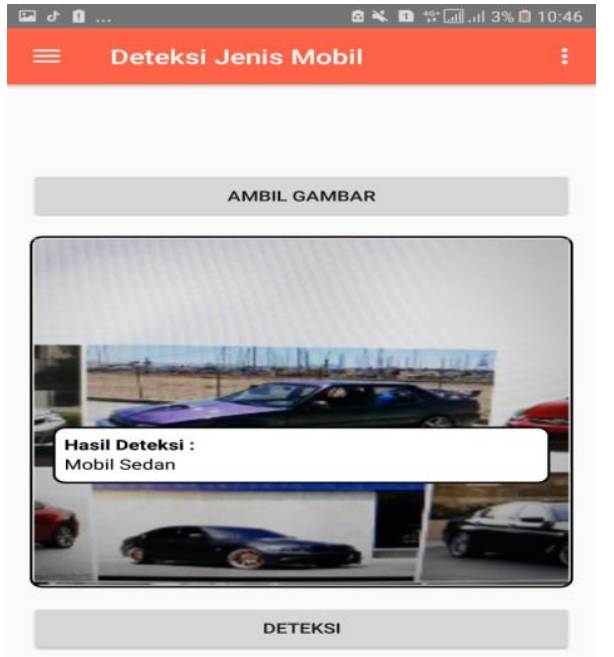

Gambar 4. User Inteface Deteksi Jenis Mobil

Dimana terlihat hasil deteksi dari gambar adalah mobil sedan. Hal ini tentu sesuai dengan gambar yang telah diinput.

\section{Kesimpulan}

Kesimpulan dari penelitian ini yaitu terbukti bahwa metode Extreme learning machine (ELM) menghasilkan akurasi yang baik dalam mengklasifikasikan jenis kendaraan dengan total akurasi $92 \%$ dengan melalui tahap 3999 epoch dalam proses training.

\section{Referensi}

Arifin, M. H. R. (2021). Deep Learninng. In Institut teknologi nasional.

Fadilla, I., Adikara, P. P., \& Perdana, R. S. (2018). Klasifikasi Penyakit Chronic Kidney Disease ( CKD ) Dengan Metode Extreme learning machine ( ELM ). Jurnal Pengembangan Teknologi Informasi Dan Ilmu Komputer, 2(10), 3397-3405. https://www.researchgate.net/profile/Ri zal Perdana/publication/323365845 KI asifikasi_Penyakit_Chronic_Kidney_Di sease_CKD_Dengan_Menggunakan_ Metode_Extreme_Learning_Machine ELM/links/5a9023c5aca272140561888 1/Klasifikasi-Penyakit-Chronic-KidneyDisease-CKD-

Najar, A. M., Magister, P., Matematika, D., Matematika, F., Dan, K., \& Data, S. (2018). Penerapan Metode Extreme learning machine Untuk Prediksi Tingkat Berdasarkan Keadaan Cuaca ( Studi Kasus : Wilayah Dki Jakarta ).
Pangestuti, G. W., Usman, K., \& Purnama, B. (2016). Klasifikasi Kendaraan Roda Empat Dengan Ekstraksi Ciri Hybrid Berbasis Jaringan Syaraf Tiruan. EProceedings of Engineering, 3(Fakultas Teknik Elektro, Universitas Telkom), 1619-1627.

Pratomo, A. H., Kaswidjanti, W., \& Mu'arifah, S. (2020). Implementasi Algoritma Region of Interest ( $\mathrm{ROI}$ ) Untuk Meningkatkan Performa Algoritma Deteksi Dan Klasifikasi Kendaraan. Jurnal Teknologi Informasi Dan IImu Komputer (JTIIK), 7(1), 155-162. https://doi.org/10.25126/jtiik.20207171 8

Priyambodo, P. (2018). Analisis Korelasi Jumlah Kendaraan dan Pengaruhnya Terhadap PDRB di Provinsi Jawa Timur. Warta Penelitian Perhubungan, 30(1),

59. https://doi.org/10.25104/warlit.v30i1.63 4

Purwaningsih, E. (2016). Seleksi Mobil Berdasarkan Fitur Dengan Komparasi Metode Klasifikasi Neural Network, Support Vector Machine, Dan Algoritma C4.5. Jurnal Pilar Nusa Mandiri, XII(2), 153-160.

https://ejournal.nusamandiri.ac.id/index .php/pilar/article/view/269

Roihan, A., Sunarya, P. A., \& Rafika, A. S. (2020). Pemanfaatan Machine learning dalam Berbagai Bidang: Review paper. IJCIT (Indonesian Journal on Computer and Information Technology), 5(1), 7582.

https://doi.org/10.31294/ijcit.v5i1.7951 
Santoso, A., \& Ariyanto, G. (2018). Implementasi Deep Learning Berbasis Keras Untuk Pengenalan Wajah. Emitor: Jurnal Teknik Elektro, 18(01), 15-21.

https://doi.org/10.23917/emitor.v18i01. 6235

Sidharta, H. A. (2017). INTRODUCTION TO OPEN CV. Binus University. https://binus.ac.id/malang/2017/10/intr oduction-to-open-cv/ 